University of New Hampshire

University of New Hampshire Scholars' Repository

6-1993

\title{
Acoustic properties of fine-grained sediments from Emerald Basin: Toward an inversion for physical properties using the Biot-Stoll model
}

\author{
Robert C. Courtney \\ Geological Survey of Canada \\ Larry A. Mayer \\ University of New Hampshire, larry.mayer@unh.edu
}

Follow this and additional works at: https://scholars.unh.edu/ccom_affil

Part of the Geology Commons, Oceanography and Atmospheric Sciences and Meteorology Commons, and the Sedimentology Commons

\section{Recommended Citation}

The following article appeared in: R. C. Courtney, 'Acoustic properties of fine-grained sediments from Emerald Basin: Toward an inversion for physical properties using the Biot-Stoll model', The Journal of the Acoustical Society of America, vol. 93, no. 6, p. 3193, 1993. and may be found at http://dx.doi.org/ $10.1121 / 1.405703$

This Article is brought to you for free and open access by the Center for Coastal and Ocean Mapping at University of New Hampshire Scholars' Repository. It has been accepted for inclusion in Affiliate Scholarship by an authorized administrator of University of New Hampshire Scholars' Repository. For more information, please contact Scholarly.Communication@unh.edu. 


\title{
Acoustic properties of fine-grained sediments from Emerald Basin: Toward an inversion for physical properties using the Biot-Stoll model
}

\author{
Robert C. Courtney \\ Geological Survey of Canada, Atlantic Geoscience Centre, Dartmouth, Nova Scotia B2Y 4A2, Canada \\ Larry Mayer \\ Ocean Mapping Group, Department of Survey Engineering, University of New Brunswick, Fredericton, \\ New Brunswick E3B 5A3, Canada
}

(Received 18 April 1991; accepted for publication 1 February 1993)

\begin{abstract}
Acoustic data from two long cores, comprising marine clays and silts taken from Emerald Basin off Nova Scotia, are presented. High-resolution measurements of compressional wave velocity, attenuation, and power law exponent are made using ultrasonic frequencies between 100 to 1000 $\mathrm{kHz}$. The observed values of the frequency dependence of attenuation suggest that a nonconstant $Q$ mechanism is needed to explain these data, and Biot-Stoll theory is used to model the experimental results. An inversion scheme is used to constrain physical parameters in the Biot-Stoll dispersion relation. The inversion shows that there is a restricted range of permeability and grain size. By assigning reasonable values for grain size in the inversion, the Biot-Stoll model predicts unique values for the permeability and frame bulk modulus that agree well with estimates made by other means.
\end{abstract}

PACS numbers: 43.30.Pc, 43.30.Ma

\section{INTRODUCTION}

Given the high degree of variability in seafloor materials, a regional understanding of the composition and geologic nature of the seabed can be practically achieved only using remote sensing acoustic techniques. Consequently, much effort has been spent trying to interpret the manner in which the acoustic response of the seabed reflects its physical, geotechnical, and geological character. New quantitative and specialized sonar equipment ${ }^{1}$ is currently being developed to measure remotely acoustic properties in an integrated manner. However, any analysis of sonar data demands a clear and focused understanding of the basic physical mechanisms that determine acoustic propagation through the sediments. These mechanisms are best investigated with controlled and direct measurements on sediment samples, uncomplicated by structural effects that may dominate in the natural environment.

Much acoustic research has concentrated on the measurement of acoustic wave velocity and attenuation and the variation of these parameters with frequency. In general, sound pressure amplitude is believed to decay exponentially with passage through sediments and the attenuation may be parametrized by ${ }^{2}$

$$
\alpha=k f^{N} \text {, }
$$

where $\alpha$ is the acoustic attenuation coefficient $(\mathrm{dB} / \mathrm{m}), k$ is a constant, $f$ is the frequency of the acoustic wave $(\mathrm{Hz})$, and $N$ is the power law exponent.

A continuing debate in the literature concerns the value of the frequency exponent and the nature of attenuation in marine sediments. Hamilton, ${ }^{3-6}$ in a long series of papers, contends that the effects of a constant $Q$ mechanism is observed in a wide range of laboratory and field data, and that frictional sliding between sediment grains dominates intrinsic attenuation. Biot ${ }^{7-10}$ and Stoll ${ }^{2,11-13}$ contend that the frequency exponent depends on the nature of the sediment structure and the frequency range of the measurement, and that both grain boundary sliding and dissipation of energy by relative pore fluid viscous flow may be important. A recent review by Kibblewhite ${ }^{14}$ summarizes the debate between the two viewpoints. In a reanalysis of low-frequency data, Kibblewhite contends that the effects of a power law exponent can be recognized in low-frequency data.

In this paper, ultrasonic compressional wave velocity, attenuation, and power law exponent data, from highporosity cored marine sediments taken from a Quaternary sedimentary basin offshore Nova Scotia, are reported. The observed power law exponent of these data is consistently greater than one and Biot-Stoll theory is used to model these data. An inversion scheme is developed to estimate acoustic constraints on the variation of bulk frame modulus and permeability in the core.

\section{BIOT-STOLL THEORY}

Biot-Stoll theory ${ }^{2}$ views a sediment as an isotropic, porous assemblage of solid grains held apart by skeletal contacts and containing void space saturated with gas or fluid. Compressional $(P)$ and shear $(S)$ waves traveling through this structure are attenuated by two physical mechanisms: (1) frictional grain to grain contact sliding and (2) viscous dissipation caused by relative motion between the grain and the interstitial fluid. This acoustic model predicts that both the velocity and attenuation of compressional and shear waves are dependent on frequency. Ogushwitz ${ }^{15-17}$ has shown that Biot-Stoll theory 
can be used to model marine acoustic velocity and attenuation data for artificial and natural materials with porosities ranging from $2 \%$ to $100 \%$.

The reader is referred to Ogushwitz ${ }^{15-17}$ or Stoll $^{2}$ for recent and more complete derivations of the Biot-Stoll formulation than is presented here. In this paper, we will deal solely with the compressional wave behavior in the ultrasonic frequency band $(100-1000 \mathrm{kHz})$ for sediments with porosities greater than $50 \%$.

We consider a sediment with a porosity $\phi$ with a fluid density $\rho_{f}\left(\mathrm{~kg} / \mathrm{m}^{3}\right)$ and a grain density $\rho_{r}$. The mean density of the composite is given by

$$
\rho(\phi)=\phi \rho_{f}+(1-\phi) \rho_{r} .
$$

The sediment has a dynamic permeability $k(\mathrm{~m} / \mathrm{s})$ and the pore fluid viscosity is $\eta$ (Pa-s).

The frequency dependence of velocity and attenuation are determined by solving two coupled differential wave equations derived by Biot, one for the interstitial fluid and one for the skeletal grains. A trial wave solution, $A e^{i(\omega t-l x)}$, is used in the coupled governing equations. This choice generates a dispersion relation for the complex wave number $l=l_{r}+i l_{i}$ for compressional and shear waves at a wave frequency $\omega$. The dispersion relation for compressional waves is given by

$$
\left|\begin{array}{cc}
H l^{2}-\rho \omega^{2} & \rho_{f} \omega^{2}-C l^{2} \\
C l^{2}-\rho_{f} \omega^{2} & m \omega^{2}-M l^{2}-i \omega \eta F(\kappa) / k
\end{array}\right|=0 .
$$

The constants, $H, C$, and $M$, are functions of the elastic moduli of the grains, skeletal frame, and fluid:

$$
\begin{aligned}
& H=\left(K_{r}-K_{b}\right)^{2} /\left(D-K_{b}\right)+K_{b}+4 \mu_{b} / 3, \\
& C=K_{r}\left(K_{r}-K_{b}\right) /\left(D-K_{b}\right),
\end{aligned}
$$

and

$$
M=K_{r}^{2} /\left(D-K_{b}\right),
$$

where

$$
D=K_{r}\left[1+\phi\left(K_{r} / K_{f}-1\right)\right] .
$$

Here, $K_{r}$ and $K_{f}$ are the bulk moduli of the grains and the fluid, respectively, while $K_{b}$ and $\mu_{b}$ are the bulk and shear moduli of the skeletal frame, respectively. Anelastic effects of grain contact sliding may be modeled by making the elastic parameters complex. ${ }^{2}$

The mass factor $m$ accounts for the apparent increase of inertia induced by the tortuosity of the pores

$$
m=a^{\prime}\left(\rho_{f} / \phi\right),
$$

where $a^{\prime}$ is the structure factor: ${ }^{15}$

$$
a^{\prime}=1-r_{0}\left(1-\phi^{-1}\right) \text {. }
$$

For spherical particles, $r_{0}=1 / 2$ (see Ref. 18).

The frequency-dependent flow of fluid in the pore space is given by the factor

$$
F(\kappa)=\kappa T(\kappa) / 4[1+2 i T(\kappa) / \kappa],
$$

where

$$
T(\kappa)=\left[\operatorname{ber}^{\prime}(\kappa)+i \operatorname{bei}^{\prime}(\kappa)\right] /[\operatorname{ber}(\kappa)+i \operatorname{bei}(\kappa)],
$$

and

$$
\kappa=a \sqrt{\omega \rho_{f} / \eta} .
$$

Note that bei and ber are complex Kelvin functions and $a$ is the pore size parameter. In high-porosity materials, ${ }^{16}$ the pore size parameter $a$ can be calculated as a function of the grain size $d$ and the porosity $\phi$ :

$$
a=d \phi / 3(1-\phi) .
$$

Estimates of the shear modulus $\mu_{b}$ for the frame are related to the bulk modulus of the frame $K_{b}$ by

$$
\mu_{b}=3 K_{b}(1-2 \sigma) / 2(1+\sigma),
$$

where Poisson's ratio, $\sigma=0.3$, is appropriate for clays. ${ }^{15}$

The dispersion relation [Eq. (3)] has two distinct complex roots of the form $l=l_{r}+i l_{i}$. The wave velocity for each root is given by $\omega / l_{r}$ and the attenuation by $l_{i}$. One solution corresponds to a relatively slow wave with high attenuation, the so-called Biot "slow wave," while the other root corresponds to the usual, higher velocity, acoustic wave. Plona $^{19}$ has observed the slow wave ${ }^{18}$ in a carefully designed experiment using a sintered, composite material; in marine sediments, only the fast wave has been measured.

The theory predicts that the attenuation, when dominated by viscous flow losses in the pore space of the sediment, will vary as the second power of frequency for low frequencies and will vary as the square root of frequency for high frequencies. ${ }^{2}$ The ratio of the cross-sectional length scale of the pore space in the sediments to the wavelength of the acoustic wave determines the boundary between high and low frequencies. Frictional loss mechanisms, in contrast, exhibit a linear dependence of attenuation.

Biot-Stoll theory is complicated, with more than ten physical parameters affecting the dispersion relation. Some of the parameters are directly measurable or known a priori (e.g., grain density, saturated bulk density, and fluid viscosity). Other material values are well constrained or vary little (e.g., elastic moduli of the grains and interstitial fluid). However, the parameters that are directly related to the grain geometry and the nature of the grain contacts are not well known (e.g., pore size parameter, mass factor, and elastic moduli of the frame) and their values are usually inferred from, or constrained by, empirical data.

\section{EXPERIMENTAL DATA}

The Emerald Basin (Fig. 1) contains a thick proglacial sediment sequence typical of deposits on the continental shelf of southeastern Canada. The basin comprises mainly fine grained silts and clays overlying glacial till deposited during the retreat of icecaps and shelf ice during the last 15000 years. ${ }^{20}$ Emerald Basin has been chosen for acoustic testing by researchers at the Atlantic Geoscience Centre because the region is well surveyed by highresolution seismic data, the stratigraphy is relatively simple and flat lying, there exists extensive core and bottom sam- 


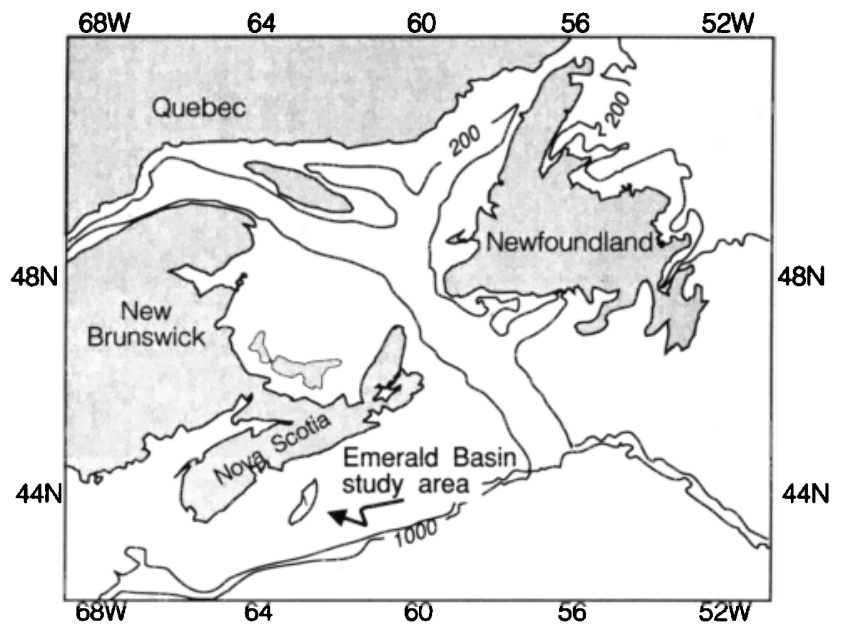

FIG. 1. Map of Southeastern Canada showing location of Emerald Basin. A very small line near the Emerald Basin label shows the position and orientation of the profile shown in Fig. 2.

ple data from previous cruises, and it is easily accessible by oceanographic ships operating out of Halifax.

A series of wide diameter $(11 \mathrm{~cm})$, long, piston cores $^{21}$ were collected on CSS HUDSON cruise 87003 (April 1987). We present acoustic data from two long cores taken from the top $20 \mathrm{~m}$ of the sediments in Emerald Basin, LCF2 (core \# 87003-002) and LCF4 (87003-004). LCF2 is located at $44^{\circ} 00.93^{\prime} \mathrm{N}, 63^{\circ} 02.04^{\prime} \mathrm{W}$ in $215 \mathrm{~m}$ of water and LCF4 is located at $43^{\circ} 53.1^{\prime} \mathrm{N}, 62^{\circ} 47.7^{\prime} \mathrm{W}$ in $235 \mathrm{~m}$ of water. These cores penetrated two major acousticstratigraphic units (Fig. 2), the LaHave Clay unit overlying the Emerald Silt. The piston cores appear to have penetrated to the acoustic basement, which is normally interpreted as an unconsolidated glacial till.

It should be noted that these stratigraphic units represent acoustic facies based on their acoustic signatures and they are not necessarily related to grain size differences. For example, in Fig. 3, the cumulative grain size data in LCF2 are plotted against depth in the core. Although some grain size variation is apparent, the grain size distribution is almost constant, with a median grain size near $2 \mu \mathrm{m}$. Grain size measurements in LCF4 (not shown), although less densely spaced, suggest a similar grain size variation.

Cores were processed on the ship within $24 \mathrm{~h}$ after collection and a full suite of geological and geotechnical

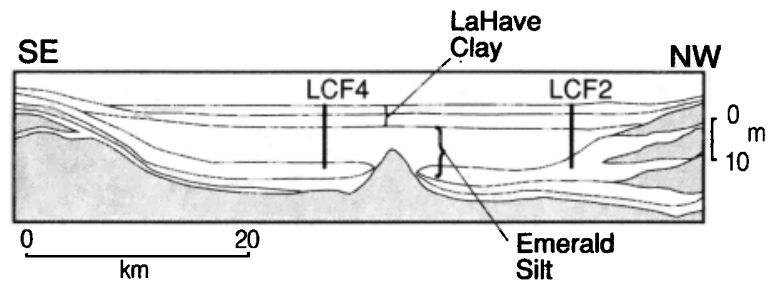

FIG. 2. Schematic cross section of central Emerald Basin showing locations of cores, LCF2 and LCF4, presented in this study. Stippled areas represent acoustically incoherent sediments. (Adapted from Gipp and Piper. ${ }^{21}$ )

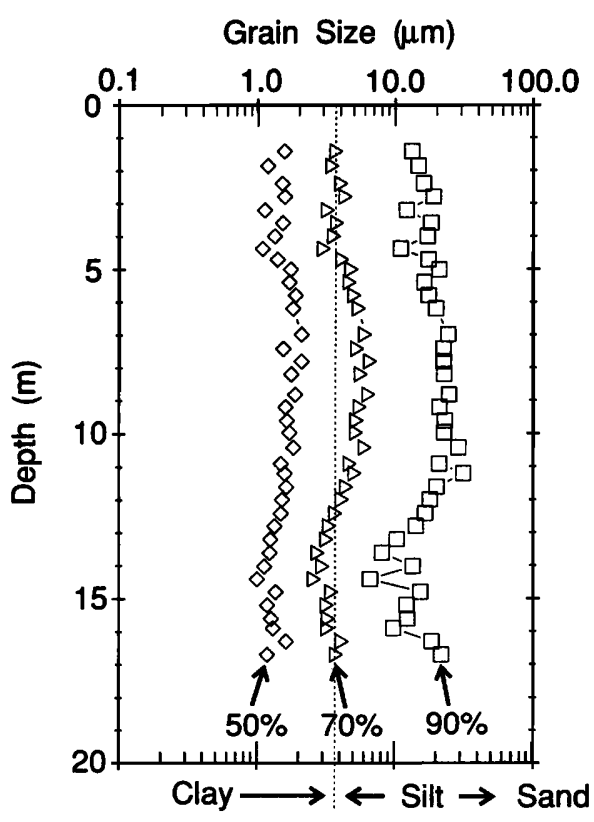

FIG. 3. Cumulative grain size data on core LCF2. Passing grain size fractions ${ }^{23}(50 \%, 70 \%$, and $90 \%)$ span the clay/silt boundary.

data was collected. The measurements included shear vane strength, bulk density, and water content. The split cores were photographed and documented, and one half was saved for archival purposes. Bulk samples were collected in order to measure grain size and grain density.

Ultrasonic compressional wave information was collected at 10- to 20-cm intervals down each core with the Dalhousie Sound Velocimeter (Fig. 4). At each position, a measurement was made both along the longitudinal axis of the split core and across the core (transverse), with the acoustic ray paths crossing the same volume of material. Much of the sediment showed color banding, related to changes in the chemical oxidation potential of the pore

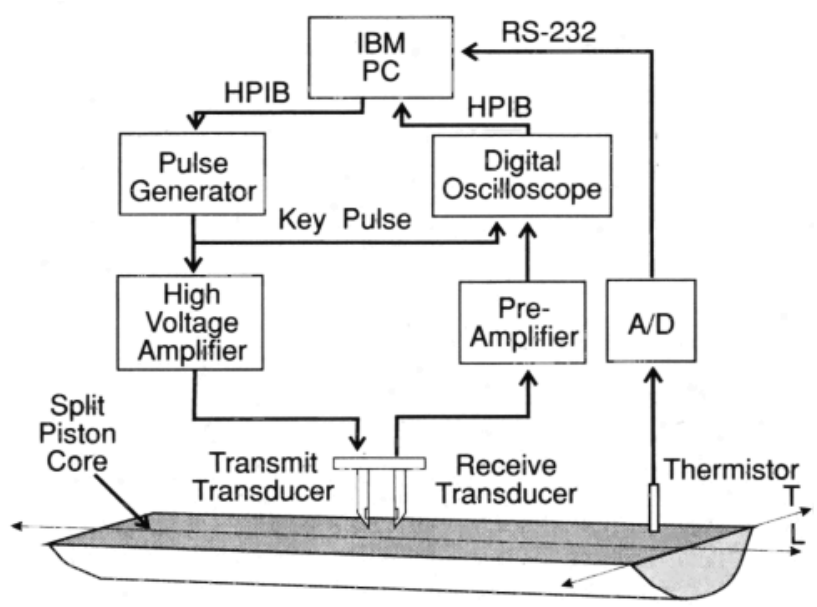

FIG. 4. Experimental setup of the Dalhousie Sound Velocimeter (DSV). An IBM PC acts as a central controller over an HPIB parallel interface. Software control triggers a pulse generator, sending a high-voltage pulse to the transmit side of the transducer pair. Waveforms received on the other transducer are amplified and then digitized in a digital oscilloscope. Digital waveforms are stored on disk on the PC. Temperatures are logged via a serial RS-232 line. 
water. Deformation of this banding across the longitudinal axis of the core was used to assess sample disturbance, and disturbed samples were rejected.

The two pairs of ultrasonic ( 100 to $1000 \mathrm{kHz}$ ) transducers were imbedded directly into the core; a $2 \mu \mathrm{s}$, high voltage pulse was applied to the transmitter of each pair in turn. The compressional waveform transmitted across the core material was digitized at $20 \mathrm{MHz}$ by a digital storage oscilloscope and recorded on magnetic disk in a personal computer. The transducer pairs had a fixed transmitterreceiver separation of approximately $0.070 \mathrm{~m}$ (longitudinal axis) and $0.045 \mathrm{~m}$ (transverse axis).

Preliminary estimates of the compressional wave velocity at each measurement position were made automatically by the computer with a simple time-of-flight method. The separation between the transmitter and receiver of each pair was measured before and after the core measurements with a vernier caliper of nominal precision 0.00002 $\mathrm{m}$. The transducer pair separations were recalibrated in a distilled water bath, using temperature corrected, tabulated values for the speed of sound in distilled water. Velocity determinations with this method are accurate and repeatable within $1 \mathrm{~m} / \mathrm{s}$. The waveform transmitted across the water bath was digitized and used as the reference for the attenuation determinations. The waveform data and temperature were recorded on disk during each core measurement and distilled water calibration.

The data were postprocessed to obtain estimates on compressional wave velocity, attenuation and frequency exponent. A filter-correlation method ${ }^{22}$ was used to estimate these quantities as a function of frequency between 200 and $1000 \mathrm{kHz}$. In this method, the digitized waveforms, transmitted both through distilled water and through the core, are filtered into eight frequency bins between 200 and $1000 \mathrm{kHz}$. In each frequency bin, the filtered waveforms are time shifted and cross correlated. The time shift, needed to maximize the cross correlation, is used to derive the velocity of the compressional waves in cored material calibrated to the measured compressional wave velocity of distilled water. The ratio between the mean amplitude of the calibration and core waveforms at maximum cross correlation is used to estimate total attenuation in each frequency band. The attenuation in $\mathrm{dB} / \mathrm{m}$ is calculated by dividing the total attenuation by the distance between the transducers. The log attenuation estimates from each band are plotted against $\log$ frequency. The slope of the curve is the frequency exponent. The filtercorrelation method minimizes the effect of secondary reflections from the sides of the split core; such reflections degrade estimates made by spectral slope or spectral ratio methods.

Figure 5(a) and (b) shows the measured velocity, attenuation and frequency exponent at $500 \mathrm{kHz}$ for cores LCF2 and LCF4. Velocity data are corrected to $10^{\circ} \mathrm{C}$. A profile of porosity is included for each core; it was calculated from saturated bulk density measurements taken along the core, using a specific gravity of the matrix of $2780 \mathrm{~kg} / \mathrm{m}^{3}$ (directly measured on representative core samples). This value of grain density falls within the nor-

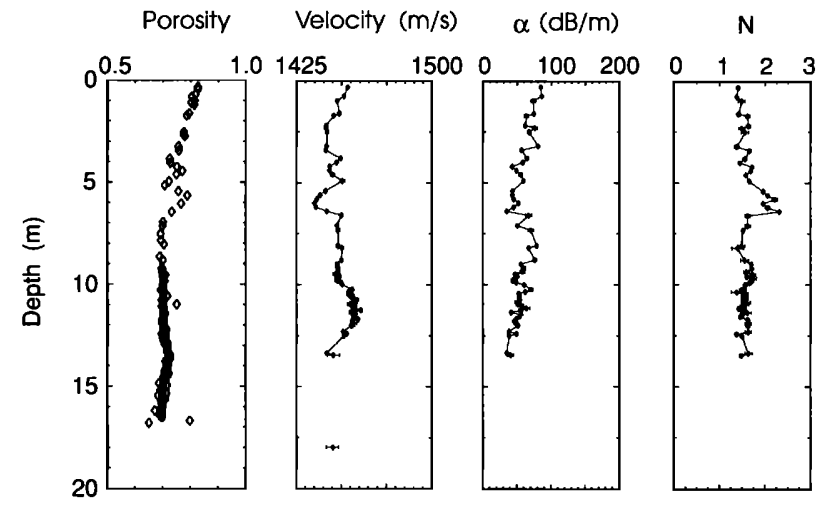

(a)

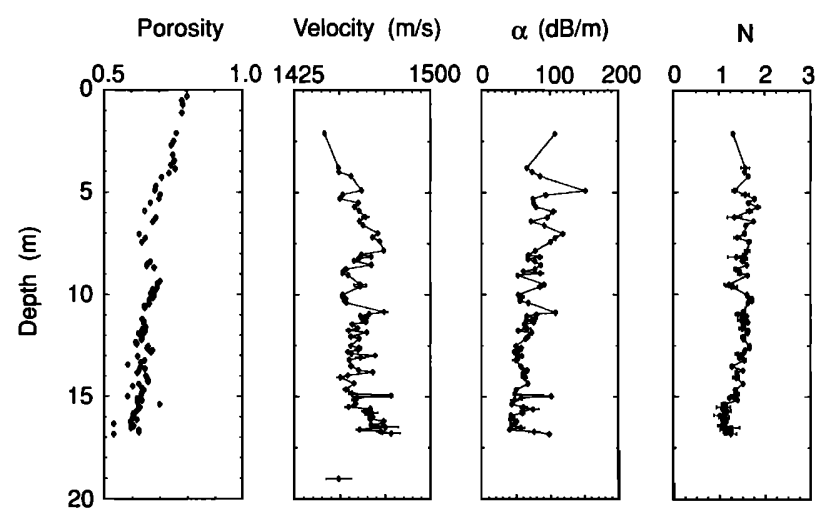

(b)

FIG. 5. (a) Measurements of porosity, velocity, attenuation and power law exponent at $500 \mathrm{kHz}$ from LCF2. At each point, both longitudinal and transverse measurements are plotted as extremes of error bars. For the most part, the error bars are too closely spaced to be visible. The porosity profile was generated from measurements of saturated bulk density made on the core assuming a grain density of $2780 \mathrm{~kg} / \mathrm{m}^{3}$. (b) Measurements of porosity, velocity, attenuation and power law exponent at $500 \mathrm{kHz}$ from LCF4.

mal range for naturally occurring clays. ${ }^{23}$ The porosities for these samples ranged from $55 \%$ to $80 \%$.

For each of the acoustic data profiles [Fig. 5(a) and (b)], the mean of the longitudinal and transverse measurements is plotted as a function of depth in the core. The error bars at each point show the deviation of the longitudinal and transverse measurements from the mean. If both longitudinal and transverse transducer pairs indeed sample the same material volume, then the measurements along both axes should be identical if the material is isotropic. However, marine sediments exhibit natural variability, even over the centimeter scale, inducing differences between the measurements along the two perpendicular paths. Anisotropy in the sedimentary structure should cause a systematic difference between longitudinal and transverse measurements. In the measurements reported here, velocity variations were generally less than $3 \mathrm{~m} / \mathrm{s}$, attenuation estimates differed by less than $10 \mathrm{~dB} / \mathrm{m}$ on average, and the frequency exponent varied by less than 0.10 on average. Measurements that fell widely outside these bounds were excluded from the analysis. Occasionally, small scale cracking of the core fabric was observed, caused by interstitial gas expansion; less than $5 \%$ of the measurements on these cores were so affected. The cracking was manifested by greatly different longitudinal and 
TABLE I. Physical parameters used in the Biot-Stoll dispersion relation.

\begin{tabular}{|c|c|c|}
\hline Parameter & Value & Comments \\
\hline $\boldsymbol{\rho}_{f}$ & $1030 \mathrm{~kg} / \mathrm{m}^{3}$ & fluid density ${ }^{15}$ \\
\hline$\rho_{r}$ & $2780 \mathrm{~kg} / \mathrm{m}^{3}$ & $\begin{array}{l}\text { matrix density; } \\
\text { measured }\end{array}$ \\
\hline$\rho$ & $1300-1900 \mathrm{~kg} / \mathrm{m}^{3}$ & $\begin{array}{l}\text { saturated bulk density; } \\
\text { measured on core }\end{array}$ \\
\hline $\begin{array}{l}\phi \\
K_{f}\end{array}$ & $\begin{array}{c}\phi=\left(\rho-\rho_{f}\right) /\left(\rho_{r}-\rho_{f}\right) \\
2.20 \times 10^{9} \mathrm{~Pa}\end{array}$ & $\begin{array}{l}\text { porosity; calculated } \\
\text { fluid bulk modulus }{ }^{16}\end{array}$ \\
\hline$\eta$ & $10.08 \times 10^{3} \mathrm{~Pa}-\mathrm{s}$ & fluid viscosity ${ }^{15}$ \\
\hline $\boldsymbol{K}_{r}$ & $4.37 \times 10^{10} \mathrm{~Pa}$ & grain bulk modulus ${ }^{16}$ \\
\hline$K_{b}$ & $10^{6}-10^{10} \mathrm{~Pa}$ & $\begin{array}{l}\text { frame bulk modulus; } \\
\text { assigned in inversion }\end{array}$ \\
\hline$d$ & $0.1-100 \mu \mathrm{m}$ & $\begin{array}{l}\text { grain diameter; } \\
\text { assigned in inversion }\end{array}$ \\
\hline$k$ & $10^{-11}-10^{-8} \mathrm{~m} / \mathrm{s}$ & $\begin{array}{l}\text { permeability: } \\
\text { assigned in inversion }\end{array}$ \\
\hline
\end{tabular}

transverse measurements and a precipitous reduction in the amplitude of the transmitted energy. These measurements were discarded.

The porosity and acoustic data show a change at about 6 to $8 \mathrm{~m}$ below top of core, roughly corresponding to the seismic LaHave clay-Emerald silt transition. LCF4, found in a deeper part of Emerald Basin, shows lower porosities in the lower section of the core, probably attributable to a slightly coarser grain size or increased compaction. Attenuation is quite variable in the top section, but generally higher than the values found in the deeper, lower porosity sections of each core. Attenuation ranges from around 100 $\mathrm{dB} / \mathrm{m}$ at $500 \mathrm{kHz}$ at the top to around $50 \mathrm{~dB} / \mathrm{m}$ in the lower section. The frequency exponent is consistently greater than unity, with a mean value ranging between 1.2 and 2.0. There is some degree of fine scale correlation between data collected for LCF2 and LCF4. Given that these cores are about $20 \mathrm{~km}$ apart implies a consistency of geologic processes throughout the basin.

\section{APPLICATION OF BIOT-STOLL THEORY}

In this study, we attempt to invert the acoustic data to generate estimates of grain size, permeability, and bulk frame modulus. It should be noted that grain size enters the dispersion relation by functionally controlling the inter-grain pore space [Eq. (7)]. The values of the other parameters in the dispersion relation were assigned beforehand. Porosity values were calculated from measurements of bulk density and water content taken on the core. The grain densities vary little, and a single value was used in the inversion. Other controlling parameters are assigned $a$ priori from the literature; Table I lists the sources.

Values of velocity, attenuation, and frequency exponent, predicted by the dispersion relation, were calculated over ranges of values for the permeability, grain size, and frame elastic moduli. Results were generated for gridded grain sizes $(d)$ ranging from 0.1 to $100 \mu \mathrm{m}$, the permeability $(k)$ ranging from $10^{-11}$ to $10^{-8} \mathrm{~m}^{2}$, and the bulk frame moduli $\left(K_{b}\right)$ ranging from $10^{6}$ to $10^{10} \mathrm{~Pa}$. These predictions of velocity, attenuation, and frequency exponent were compared to measurements on the core.

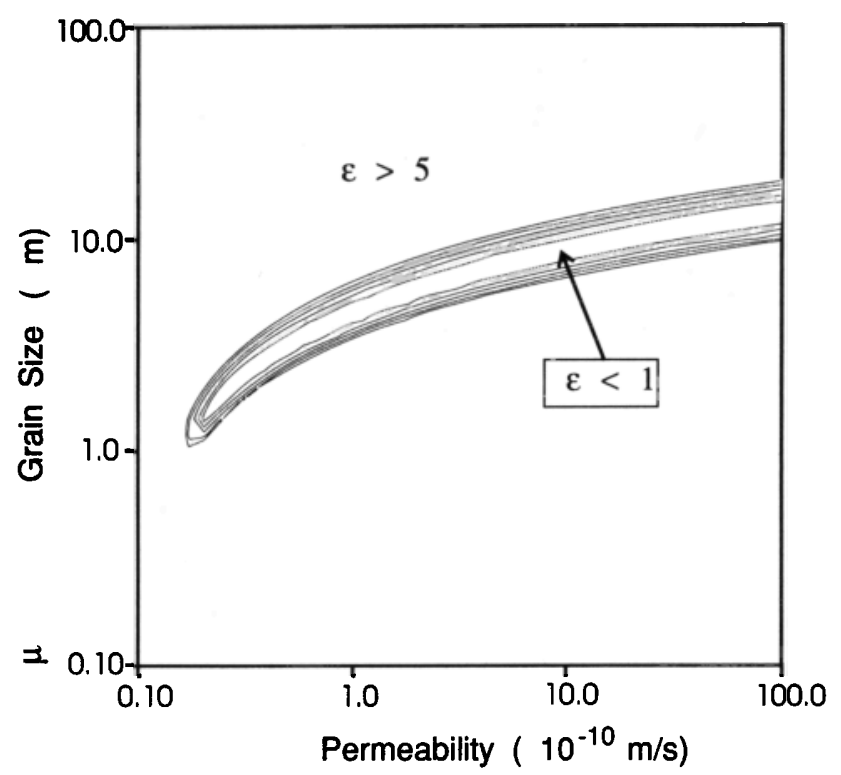

FIG. 6. Contours of the objective function $\epsilon_{i}$ over gridded values of grain size and permeability, with the frame bulk modulus fixed at $3 \times 10^{7} \mathrm{~Pa}$. Contour levels range from 5 (outermost) to 1 (innermost).

In order to quantify the fit of the predictions to the observed data, a simple objective function $\epsilon_{i}$ was defined:

$$
\epsilon_{i}=\sqrt{\frac{\left(v_{i}-v_{b}\right)^{2}}{\delta v_{i}^{2}}+\frac{\left(\alpha_{i}-\alpha_{b}\right)^{2}}{\delta \alpha_{i}^{2}}+\frac{\left(N_{i}-N_{b}\right)^{2}}{\delta N_{i}^{2}}},
$$

where $v_{i}, \alpha_{i}$, and $N_{i}$ are the mean between longitudinal and transverse empirical estimates and $v_{b}, \alpha_{b}$, and $N_{b}$ are the Biot-Stoll estimates at each measurement position ranging from the top $(i=1)$ to the bottom $(i=n)$ of the core. The weights $\delta v_{i}, \delta \alpha_{i}$, and $\delta N_{i}$ are taken from the difference between longitudinal and transverse measurements at each measurement position. Minimum values for each weight were assigned when the longitudinal and transverse measurements agreed more closely. In this paper, the minimum value for $\delta v_{i}$ was taken as $5 \mathrm{~m} / \mathrm{s}, \delta \alpha_{i}$ was taken as $5 \mathrm{~dB} / \mathrm{m}$ and $\delta N_{i}$ as 0.1 . These values are based on empirical estimates of accuracy and repeatability in the measurements of the acoustic parameters. Values of $\epsilon_{i}$ falling below 1.0 signify a good match of predicted values to observed data.

Examination of the surface generated by the objective function, $\epsilon_{i}$, reveals characteristics of the governing dispersion relation. In Fig. 6 contours of $\epsilon_{i}$, for a typical core measurement, are plotted for gridded values of permeability and grain size ( $k$ and $d)$, with the bulk modulus of the frame kept at a fixed value. Acceptable solutions are restricted to a subset of the search space, but a unique solution is not defined. A continuous range of permeability and grain size values can be used to fit the observed data; generally, larger values of permeability require progressively larger values of grain size in order to match the experimental data. The acoustic data, interpreted using Biot-Stoll theory, therefore, cannot independently resolve simultaneously unique values of grain size and permeability. A direct functional relationship, possibly empirically based, between the two variables could, however, be used to con- 


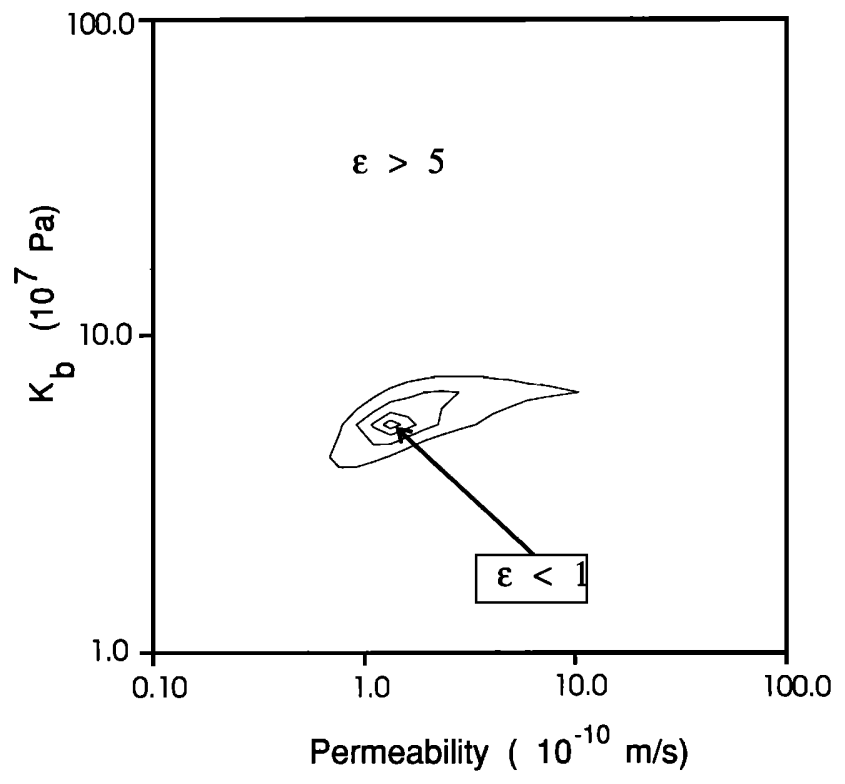

FIG. 7. Contours of the objective function $\epsilon_{i}$ over gridded values of frame bulk modulus and permeability, holding the grain size fixed at $4 \mu \mathrm{m}$. Contour levels range from 5 (outer most) to 1 (inner most).

strain the inversion. In contrast, contour plots where the frame bulk modulus and the permeability were varied, with the grain size held constant, show a unique resolvable minimum (Fig. 7). It should be noted that this minimum will change when the preassigned value of the grain size in the inversion is varied.

In Fig. 8(a) and (b), the best-fit predictions of the minimization procedure are plotted for three preassigned values of grain size $(d=2,4$, and $20 \mu \mathrm{m})$ that bracket the $60 \%$ to $90 \%$ passing limits observed in grain size analysis for these cores. A $90 \%$ passing limit of $20 \mu \mathrm{m}$ indicates that $90 \%$ of the grains in the sample have a diameter less than $20 \mu \mathrm{m}$ (see Ref. 24). The model estimates fit the observed values of velocity and attenuation within $1 \%$ on average, with no discernable difference between the predictions made with different input grain sizes.

The effects of varying grain size are most clearly observed in the plots of the power law exponent. The $2-\mu \mathrm{m}$ grain size generates a power exponent approximately equal to 2 while the larger grain sizes $(4$ and $20 \mu \mathrm{m})$ produce values of $N$ closer to 1.3. The observed data are bounded by these predictions and it is difficult to choose which of the trial grain sizes is the most appropriate. The observed data could not be modeled with grain sizes much less than $2 \mu \mathrm{m}$. Since grain size enters the dispersion relation through the definition of the pore space $a$ [Eq. (7)], caution must be taken when assessing these grain size estimates. For example, if the coefficients in the pore size definition were adjusted, then lower grain size values could be used to match the observations. It suffices to note, however, that the grain size estimates, that fit in the inversion, do correspond approximately with grain size estimates derived from direct measurement.

In summary, it is germane that, even though Biot theory cannot be used to uniquely invert compressional wave

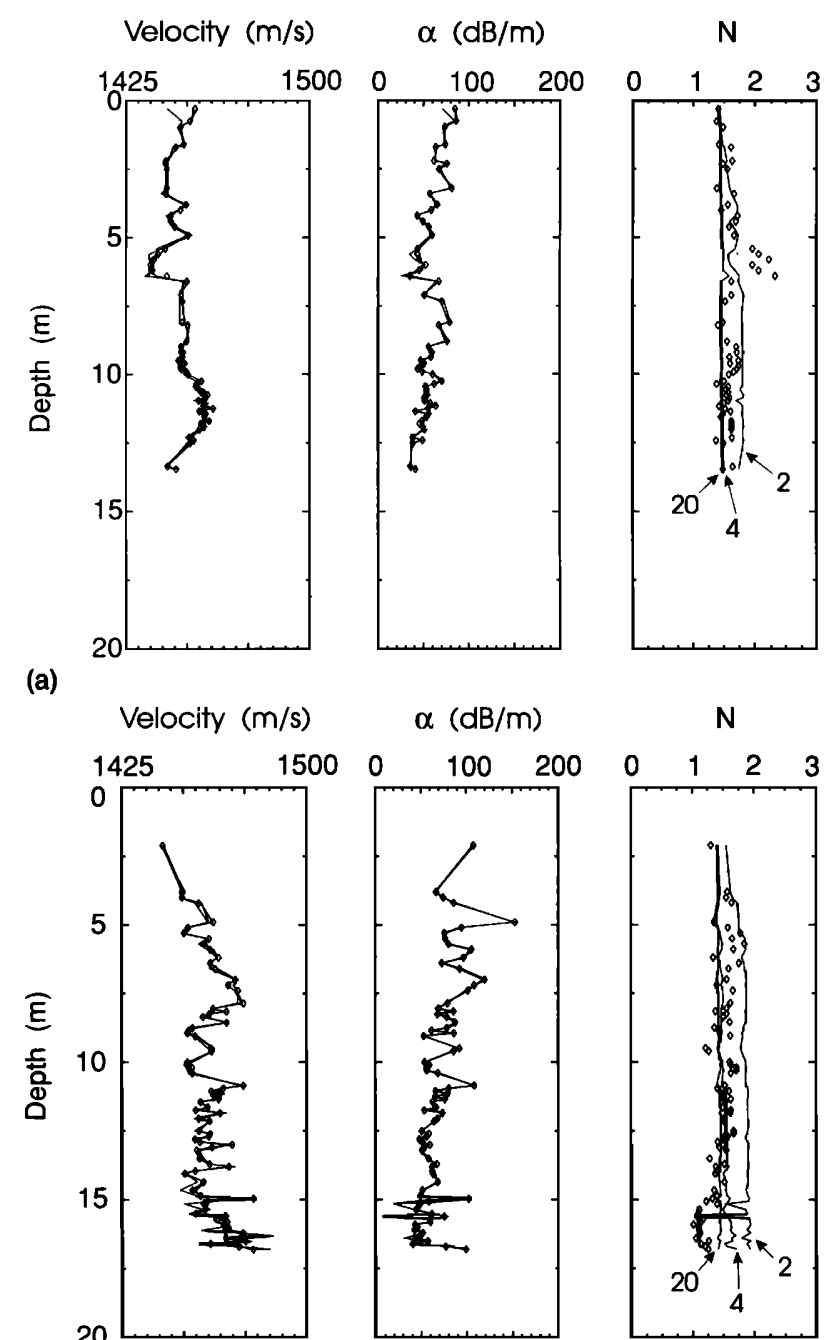

(b)

FIG. 8. (a) Biot-Stoll model inversion estimates (solid lines) fit to the experimental acoustic data (point data) for three choices of grain size (2, 4 , and $20 \mu \mathrm{m}$ ) for LCF2. On plots of velocity and attenuation, all of the fixed grain size model estimates fit the data equally well. The power law exponent generally decreases with increasing grain size. (b) Biot-Stoll model inversion estimates (solid lines) fit to the experimental acoustic data (point data) for three choices of grain size $(2,4$, and $20 \mu \mathrm{m})$ for LCF4.

velocity and attenuation data, it is possible to constrain the relationships between some of the important physical parameters. Additional stipulations, for example the imposition of a direct functional relationship between grain size and permeability, could be used to constrain the inversion to yield unique results.

As part of the inversion procedure, optimal values of $k$ and $K_{b}$ were found in order to achieve a fit for each measurement on the core. These best-fit values can be compared to estimates of permeability and frame modulus deduced by other independent means. Empirically derived estimates of permeability can be generated from relations derived from sediment samples obtained in the Gulf of Mexico: 25

$$
k=e^{(15.59 \phi-26.65)} \times 10^{-2} \mathrm{~m} / \mathrm{s}
$$

for silty sands and clayey silts.

Similarly, estimates of the dynamic frame modulus for silty 


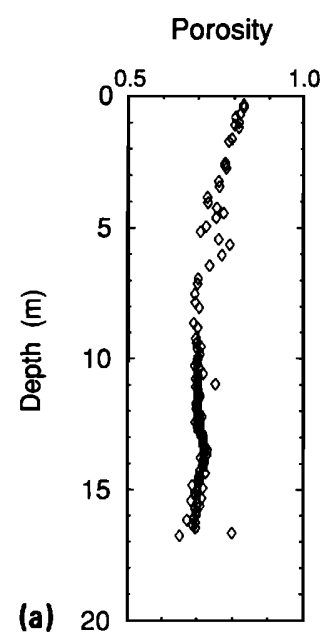

$\mathbf{k}\left(10^{-10} \mathrm{~m} / \mathrm{s}\right)$
$0.1 \quad 1 \quad 10 \quad 100$
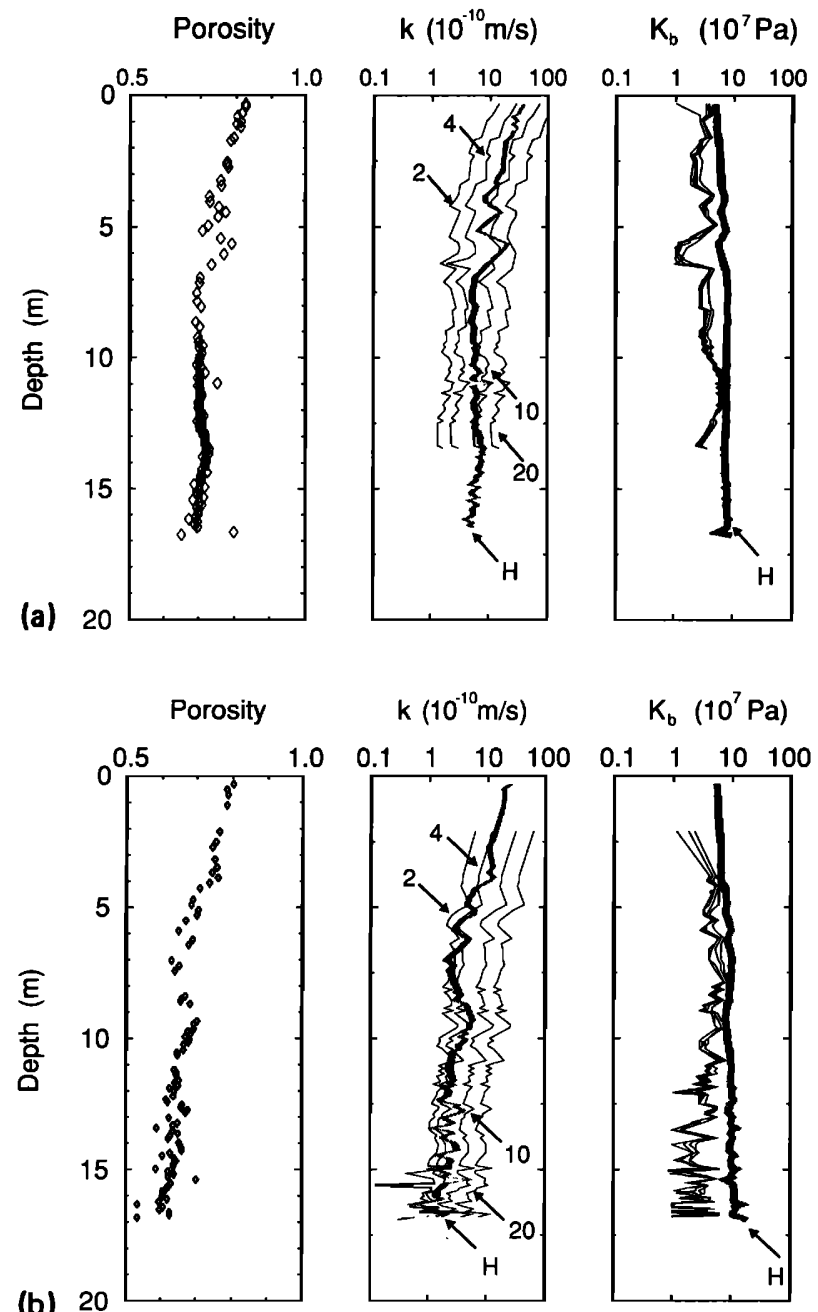

$$
\text { k }\left(10^{-10} \mathrm{~m} / \mathrm{s}\right)
$$

$$
\mathrm{K}_{\mathrm{b}}\left(10^{7} \mathrm{~Pa}\right)
$$
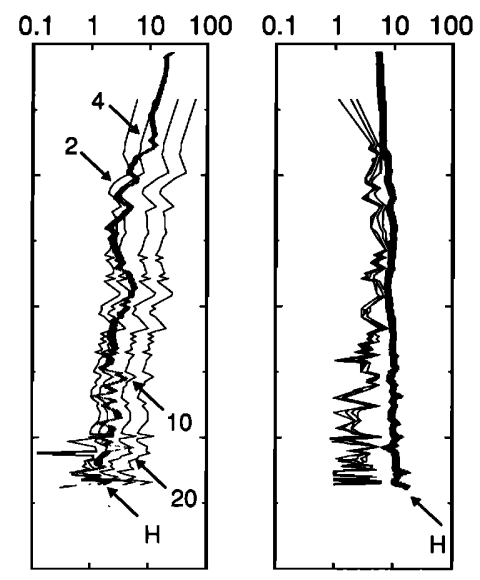

FIG. 9. (a) Plots of inversion values (solid lines) of permeability and frame modulus derived for LCF2. Inversion estimates are plotted for four preassigned grain sizes $(2,4,10$, and $20 \mu \mathrm{m})$. The heavy stippled lines, denoted by $H$, show the porosity based, empirical estimates of permeability and frame modulus discussed in the text. (b) Plots of inversion values (solid lines) of permeability and frame modulus, derived for LCF4. The heavy stippled lines, denoted by $H$, show the porosity based, empirical estimates of permeability and frame modulus.

clays with $1 \mathrm{~m}$ or less overburden pressure were derived by Hamilton $^{26}$ using

$$
K_{b}=e^{(3.73580-4.25075 \phi)} \times 10^{8} \mathrm{~Pa} .
$$

This relation is appropriate for surficial, uncemented sediments such as those sampled in the Emerald Basin cores, while it is not applicable for bonded materials or cemented sediments at low porosities. ${ }^{15}$

In Fig. 9(a) and (b) plots of inversion estimates of $k$ and $K_{b}$, as a function of depth for input grain sizes of 2, 4, 10 , and $20 \mu \mathrm{m}$ for LCF2 and LCF4, are plotted with the empirical estimates of $k$ and $K_{b}$ generated from measurements of porosity. Empirical estimates of permeability are bracketed by the inversion values for grain sizes between 2 and $10 \mu \mathrm{m}$. The degree of correlation between the empirical and inverted values is good. Inversion estimates of $K_{b}$ depend minimally on the assigned grain size.

\section{DISCUSSION}

Although not presented here, the Biot-Stoll models were tested using complex elastic frame moduli, which include the effects of grain contact sliding. Because these sediments have high porosities and small grain sizes, the magnitudes of the frame moduli needed to model the data were small and, consequently, the effects of the frictional sliding in the wave equation solutions were not significant. These sediments respond acoustically more like a suspension than a structurally competent sediment, even though the porosity approaches $55 \%$. The attenuation mechanism in these marine silty clays is dominated by viscous flow through the pore space of the sediment. Coarse slits or sands are likely to respond differently, where much lower porosities would accentuate grain to grain effects.

Inversion-based estimates of the frame bulk modulus are consistently less than estimates based on Hamilton's empirical data ${ }^{26}$ [Fig. 9(b)]. Hamilton's data were corrected to an overburden pressure of $1 \mathrm{~m}$. The magnitude of the frame modulus in an unconsolidated sediment can be shown to be a function of both the void ratio in the sediment and the average stress on the frame. ${ }^{2}$ The stresses in a split core probably vary considerably since the coring process is not uniform. There is ample evidence of variable and excess suction in the cores collected from Emerald Basin as some sections of some cores were distorted by the collapse of the core tube plastic liner. These sections were of course discarded, but the effect is most likely present to some extent in all cored material. Uneven friction between the cored sediments and the plastic core liner undoubtably induces local variations of the confining stress in the cored material. The inversion-derived estimates of frame modulus, then, likely reflect both changes in void ratio and changes in the local stress field. A direct application of these estimates to studies in a natural marine environment should be viewed with caution.

\section{v. CONCLUSIONS}

We have presented compressional wave acoustic data from high porosity marine sediments. The data show that the attenuation exponent in these sediments ranges between 1.3 and 2.0. Inversion of the acoustic data using Biot-Stoll theory shows that there is a restricted range of grain size and permeability values that can be used to fit the data. With functional constraints on the relationships between these variables, a unique model could be resolved. Given reasonable estimates of grain size, the inversion estimates of permeability agree with empirical estimates made by other means. Inversion based estimates of frame modulus are largely independent of the assigned grain size used in the inversion and are bounded by empirically derived values.

\section{ACKNOWLEDGMENTS}

The authors would like to thank the captain and crew of the CSS HUDSON for their assistance in collecting cores during the cruise 87-003. Kate Moran and Harold Christian of the Atlantic Geoscience Centre collected geotech- 
nical data used in this report. Steve Fehr made the grain size measurements. Helpful comments were given by an anonymous reviewer. Funding for this research was provided through the Office of Naval Research (Contract No. N00014-91-J-1213), the Natural Sciences and Engineering Research Council and the Department of Energy, Mines, and Resources.

${ }^{1}$ S. H. Schock, L. R. Leblanc, and L. A. Mayer, "Chirp subbottom profiler for quantitative sediment analysis," Geophysics 54, 445-450 (1989).

${ }^{2}$ R. D. Stoll, Sediment Acoustics (Springer-Verlag, New York, 1989).

${ }^{3}$ E. L. Hamilton, "Sound attenuation as a function of depth in the sea floor," J. Acoust. Soc. Am. 59, 528-535 (1976).

${ }^{4}$ E. L. Hamilton, "Geoacoustic modeling of the seafloor," J. Acoust. Soc. Am. 68, 1313-1340 (1980).

${ }^{5}$ E. L. Hamilton and R. T. Bachman, "Sound velocity and related properties of marine sediments," J. Acoust. Soc. Am. 72, 1891-1904 (1982).

${ }^{6}$ E. L. Hamilton, "Acoustic properties of sediments," in Acoustics and Ocean Bottom, edited by A. Lara-Saenz, C. Ranz Guerra, and C. CarboFite [Consejo Superior de Investigaciones Cientificas (CSIC), Madrid, 1987], pp. 30-46.

${ }^{7}$ M. A. Biot, "Theory of propagation of acoustic waves in a fluidsaturated porous solid, I. Low frequency range," J. Acoust. Soc. Am. 28, 168-178 (1956).

${ }^{8}$ M. A. Biot, "Theory of propagation of acoustic waves in a fluidsaturated porous solid, II. Higher frequency range," J. Acoust. Soc. Am. 28, 179-191 (1956).

${ }^{9} \mathrm{M}$. A. Biot, "Mechanism of deformation and acoustic propagation in porous media," J. Appl. Phys. 33, 1482-1498 (1962).

${ }^{10} \mathrm{M}$. A. Biot, "Generalized theory of acoustic propagation in porous dissipative media," J. Acoust. Soc. Am. 34, 1254-1264 (1962).

${ }^{11}$ R. D. Stoll, "Acoustic waves in ocean sediments," Geophysics 42, 715725 (1977).
${ }^{12}$ R. D. Stoll, "Experimental studies of attenuation in sediments," $\mathrm{J}$. Acoust. Soc. Am. 66, 1152-1160 (1979).

${ }^{13}$ R. D. Stoll, "Theoretical aspects of sound transmission in sediments," J. Acoust. Soc. Am. 68, 1341-1350 (1980).

${ }^{14}$ A. C. Kibblewhite, "Attenuation of sound in marine sediments: A review with emphasis on new low-frequency data," J. Acoust. Soc. Am. 86, 716-737 (1989).

${ }^{15}$ P. R. Ogushwitz, "Applicability of the Biot theory. I. Low-porosity materials," J. Acoust. Soc. Am. 77, 429-440 (1985).

${ }^{16}$ P. R. Ogushwitz, "Applicability of the Biot theory. II. Suspensions," J. Acoust. Soc. Am. 77, 441-452 (1985).

${ }^{17}$ P. R. Ogushwitz, "Applicability of the Biot theory. III. Wave speeds versus depth," J. Acoust. Soc. Am. 77, 453-464 (1985).

${ }^{18}$ J. G. Berryman, "Confirmation of Biot's theory," Appl. Phys. Lett. 37, 382-384 (1980).

${ }^{19}$ T. L. Plona, "Observations of a second bulk compressional wave in a porous medium at Ultrasonic Frequencies," Appl. Phys. Lett. 36, 259_ 261 (1980).

${ }^{20}$ L. H. King, "Surficial geology of the Halifax-Sable Island map area," EMR Marine Sciences, Department of Energy, Mines, and Resources, Canada, Paper 1, 16 pp. (1970).

${ }^{21}$ L. Mayer, K. Moran, D. Piper, and R. C. Courtney, "Long cores from Emerald Basin: Physical and acoustic properties," EOS Trans. Am. Geophys. Union 68, 1324 (1987).

${ }^{22}$ R. C. Courtney and L. A. Mayer, "Calculation of acoustic parameters by a filter-correlation method," J. Acoust. Soc. Am. 93, 1145-1154 (1993).

${ }^{23}$ M. R. Gipp and D. J. W. Piper, "Chronology of Late Wisconsinan glaciation, Emerald Basin, Scotian Shelf," Can. J. Earth Sci. 26, 333335 (1989).

${ }^{24}$ B. M. Das, Advanced Soil Mechanics (McGraw-Hill, New York, 1983), p. 10.

${ }^{25}$ W. R. Byrant, W. Hottman, and P. Trabant, "Permeability of unconsolidated and consolidated marine sediments, Gulf of Mexico," Mar. Geotech. 1, 1-14 (1975).

${ }^{26}$ E. L. Hamilton, "Elastic properties of marine sediments," J. Geophys. Res. 76, 579-604 (1971). 